Departamento de Anatomia da Faculdade de Medicina da Universidade de São Paulo

(Dir. Prof. R. LOCCHI)

\title{
Pesquisas anátomo-comparativas sobre o foramen o esophagicum do diafragma em Mamíferos silvestres brasileiros
}

\section{R. Locchi}

Em nota preliminar publicada ha alguns anos (1934), tive ocasião de registar o particular modo pelo qual é delimitado o for amen oesophagicum do diafragma no Dasypus novemcinctus observado em 6 exemplares, prometendo tratar outra vez do assunto assim que conseguisse maior número de casos, para melhor julgamento do valôr do achado. Dispondo porém de diafragmas de outras espécies de Mamíferos silvestres da Fáuna brasileira resolvi extender minhas observações e consequentemente apresentar mais uma contribuição para o conhecimento da anatomia desses Mamíferos, ainda pouco investigada sistematicamente e por isso não bem conhecida. Este trabalho é assim, mais um natural tributo, mínimo, de gratidão e homenagem ao pranteado Mestre A. Bovero, de quem muitos receberam o incitamento para desenvolver pesquisas, sempre interessantes, de morfologia comparativa em espécies silvestres de Mamíferos do Brasil.

As minhas pesquisas tratam pois, da morfologia da pars lumbalis do diafragma, no que concerne o comportamento dos feixes dos chamados pilares lombares (mediais) direito e esquerdo na limitação do for amen oesophagicum (f.oe.), exclusivamente em Mamíferos silvestres do Brasil. Propositadamente selecionei assim o material, não só porquê em muitas das especies examinadas essa questão ainda não foi abordada, pelo que sei, como tambem porquê melhor se prestam os resultados para um confronto com os oriundos de pesquisas em espécies não domesticas, de outras regiões, e ampliação de eventuais dados já conhecidos mesmo de exemplares de espécies nossas, dissecados por outros AA.. 
O interesse morfológico geral do assunto em questão ressalta da literatura abaixc, especialmente das pesquisas e conclusões de Körner (1929, 1931. 1932) que passo a resumir em primeiro lugar.

\section{Literatura}

Körner (1929), partindo das observações de Stadtmüller e Stenzel 1926) de que no homem o f.oe. é limitado, como disposição de muito a mais frequente, apenas pelo pilar medial direito cujos feixes musculares rodeiam o esofago pela direita e pela esquerda (diferentemente do que se lê nos Tratados de Anatomia em geral, nos quais vem descrito um cruzamento de feixes dos dois pilares antimeros, ámbos assim constituindo o f.oe.)* e de que si ha feixe do pilar esquerdo cruzado para a direita onde limita o f.oe. é êle de situação ventral aos demais, não limitando êsse foramen quando dorsal, Körner, digo, por sugestão de Stadtmüller, procura verificar em Mamiferos outros, qual a disposição dos feixes limitantes o f.oe., para confrontar com a disposição encontrada no Homem e determinar o significado das suas modalidades. Depois de uma revisão da bibliografia, representada principalmente pelos Tratados de Anatomia veferinária, nos quais. já se nota divergência quanto ao pilar lombar que fórma o f.oe., além das poucas pesquisas em animais silvestres, apresenta Körner as observações pessoais. Compreendem estas 82 diafragmas de Mamíferos domésticos ou não, representantes de $M$ a r s u p i lia Insectivora Carnivora Pinnipedia Edentata, Rodentia Un gulata e Primates $\AA$ parte algumas diferenças, que não interessam no mo. mento, as dissecções demonstram que em todos os casos o f. ore. é limitado somente pelo pilar direito, apresentando-se o f.oe. como uma fenda ou botoeira mais ou menos. nítida dêsse pilar, e, a não ser um caso, único, de O taria Stelleri jamais en. controu um feixe do pilar esquerdo cruzando para a direita. Aliás, nêsse caso o feixe esquerdo, se bem que de situação ventral, não concorria á delimitação propriamente do f.oe., cujos contornos direito e esquerdo eram constituidos sômente por feixes originados do pilar direito. O A., em face das suas observações, conclue que a disposição de um f.oe. formado à custa unicamente, do pilar direito, representaria uma primitive Variante por ser a fundamental, de partida, encontrada na generalidade dos mamiferos; ao passo que a presença de feixes musculares com origem no pilar esquerdo cruzados á direita onde contribuem à limitação do f.oe. seria a progressive Variante verificada no Homem, e ainda assim não como disposição mais frequente. Nota o A. o achado todo especial de Testut (1884): no Ursus a m e rican us ha um feixe do pilar esquerdo passado entre o esofago e aorta.

Um pouco mais tarde (1931) Körner publica uma nota especial sôbre a pars. I u m b lis do diafragma de Otaria stelleri por haver tido ocasião de dissecar mais um exemplar dessa especie. Ainda neste, o f.oe. é limitado por feixes originados do pilar direito, mas ha cruzamento de feixes dos dois pilares direito e esquerdo, entre o hiatus a orticus e o f.oe., sendo os feixes esquerdos cruzados de situação dorsol. O A. reafirma sua conclusäo supracitada dos dois tipos, primítivo e progressivo de f.oe. Quanto à presença de feixes cruzados como nos casos de Otaria

(*) Sobre a questão, para o Homem, vide: Locchi, R. - Ricerche anafomiche sul "foramen oesophagicum" del "diaphragma' in negri e meticci (mulati) brasiliani. Arquivos Cir. Clin. Exp., Vol. IV, n. I, S. Paulo, 1940. 
discute o A. sua possivel explicação, lembrando a forma do torax nêsse animal de vida aquatica não mais "kielförmig", e interpreta como um exemplo de fenómeno de "convergência" a semelhança dessa disposição com a encontrada sômente no Homem.

No âno seguinte (1932) volta Körner a tratar da anatomia do diafragma, agora em Xen arthra, dissecando um de Bradypus tridactylus um de Choloepus didactylus e um de Tamandua tetradactyla No diafragma do Br tridactylus encontra um estreito canal comum para aorta e esôfago com presença de um muito pequeno feixe muscular interposto entre os dois orgãos. No $\mathrm{Cho}$ loepus didactylus ha um largo canal, ainda comum para o esôfago e a aorta, sem feixe muscular interposto. Em ambos, os feixes musculares da pars lumbalis limitantes o canal aórtico-esofágico unem-se num rafe fibroso ou tenditieo. No caso de Ta madua tetradactyla ha um f.oe. e um hiatus aorticus, distintosi é largo o orifício para o esôfago, separado êste da aorta por estreita fita carnosa que o A., apesar da dificuldade de dizer a que pilar pertença, julga que poderia ser considerado como do pilar direito; logo, semelhante ao que existe na grande maioria dos Mamíferos. O A. tece a seguir alguns comentários sobre a interpretação da particular disposição da pars lumbalis do diafragma em Bradypodidae com um canal comum para o esôfago e a aorta, lembrando o deslocamento ventral da aorta torácica, - peculiar modo de locomoção e de repouso da Preguiça, a mobilidade da coluna vertebral, o seu comp'icado estômago. Conclue dizendo que um canal único haveria só em Bradypodidae. nos demais Xenarthra havendo um f.oe. e um hiatus aort $i$ cus separados; e quando em $X$ en a thra ha dois orifícios, as margens do f.oe. são formadas por feixes do pilar direito, como nos demais Mamíferos. Deve-se notar que antes destas conclusōes, Körner lembra a descrição dada por Pouchet (1874) para - diafragma de um Myrmecophaga iubata logo Xenarthra não Bra dypodidae no qual tambem ha um canal comum aórtico-esofágico, frizando porém, ser êsse um caso isolado.

Destaquei as pezquisas anátomo-comparativas de Körner porque mais de perto relacionadas com as minhas sôbre a anatomia do diafragma em Mamíferos da nossa fauna (Xenarthra) iniciadas antes da primeira publicação do A.. De fáto, em nota preliminar (1928) assinalei a presença de um canal aórtico-esofágico no B r trida ctilus dando a seguir (1930, 1931) os resultados completos a respeito, baseado em 20 casos dessa espécie e mais I de Br torquatus No Br iridactylus ha um canal comum para o esôfago e a aorta, sendo os feixes musculares delimitantes dêsse canal reunidos em um rafe tendíneo com inserção á esquerda da linha mediana, de modo a não ser fácil individuar um pilar medial direito $\theta$ um esquerdo. No B r torquatus a disposição é a mesma, com presença de um delgado feixe muscular interposto aos dois órgãos, semelhante ao que notou Körner no seu caso de Br tri dactylus Em outra nota, como disse, (1934) focalisei a constituição do f.oe. do diafragma em Dasypus novemcinatus segundo o exame de 6 exemplares, havendo em todos uma curiosa disposição: o f.oe. limitado exclusivamente pelo pilar esquerdo. Na mesma ocasião indiquei haver dissecado um diafragma de $\mathrm{Cab}$ assus unicinctus e l de E sexcinctus: em ambos ha um foe. limitado essencialmente pelo pilar esquerdo mas um feixe do pilar direito cruza á esquerda, dorsalmente, e vai confundir-se com os feixes do pilar esquerdo que limitam o f.oe. à esquerda. Resulta destas investigações pessoais que o diafragma nesses $\mathrm{X}$ e $\mathrm{n}$ a $\mathrm{r}$ thra mostra uma morfologia que se afasta mais ou menos daquela da maioria dos Mamiferos, confirmando assim os achados isolados de alguns AA. Refiro-me aos de $\mathrm{Hyrtl}$ (1855), Murie (1874). Pouchet (1874) e Goldschmidt (191)). Hyrtl em Chlamydoforus 
truncatus refere-se a cruzamento de feixes dos dois pilares ao nivel do f.oe. do diafragma: Murie em Tolypeutes conurus fala de um forte pilar esquerdo que segue alem do f.oe., em direção ao orificio da v. c. inf.; Pouchet descreve em Myrmecophaga jubata conforme vimos acima, um canal comum para aorta $\theta$ esôfago (in Körner, 1932). Goldschmidt menciona um oriflcio único no B $r$ tridactylus $(2$ casos) e dois orifícios num $T$ a mandua te tradactyla com o feixe muscular separante a aorta do esôfago, dirigido da direita para a esquerda. A parte lembro que Condorelli Francaviglia (1893) refere que no $B r$ tridactylus o esôfago "perfora il diaframma poco distante dal forame aortico"..

Além dessa literatura mais especialmente tratando de Xenarthra, mister se faz citar os seguintes AA.: Bertelli (1895) na sua monografia sobre anatomia do diafragma, compreendendo Mamíferos domésticos ou não, conclue que o esôfago passa através do pilar direito em Perissodactilos, Artiodáctilos, Roedores, em alguns Carnivoros, em alguns Insetivoros e alguns Primatas. Afasta-se da disposição geral, isto é, f.oe. limitado sômente pelo pilar direito, o diafragma dos seguintes animais: Cynocephalus ba buin com foe. limitado pelos dois pilares; Vesperugo nootulla com feixes musculares lombares unidos em rafe fibroso, lembrando o do gen. Bradypus, havendo um feixe minimo entre o esôfago e aorta; no Erinaceus europaeus o esôfágo passa entre os dois pilares; em $C$ a n is familiaris ha fusão dos pilares, não sendo possivel estabelecer as relações de cada um com o f.oe. Le Double (1897) lembra alguns Mamíferos nos quais o esôfago passa através do pilar direito, ao passo que no cão e no porco ha fusão dos pilares sendo dificil afirmar qual dêles limita o f.oe. Godschmidt (1911) si bem que trate da anatomia do hiatus aorticus menciona em alguns dos seus casos a disposição do f.oe. Assim, além dos casos de $\mathrm{X}$ en arthra supracitados bem como de parecer, pelas figuras do $A_{\text {., }}$ ser o f.oe. limitado pelo pilar direito em muitas das suas observações (Mamíferos domésticos e silvestres) interessante é o que encontrou em Herpestes: a limitação entre o f.oe. e o hiatus aorticus é feita por fino feixe muscular que da esquerda vai para a direita. Winckler (1926), apesar de não estudar a questão, figura a região do hiatus a orticus em Mamíferos silvestres e domésticos, representando sempre um pilar direito desdobrado, circumscrevendo o ângulo caudal do f.oe., ao menos na face (ventral) representada. - Pancrazi (1931) descreve as modalidades de comportamento dos feixes do pilar direito que cruzam para a esquerda, em relação aos constituintes do pilar esquerdo, conforme aqueles se coloquem dorsalmente ou ventralmente a êstes ou com êles se confundam. Diz que êsse feixe cruzado, que denomina porção esquerda do pilar direito, falta no delfim e na lontra. Tambem menciona um estreito feixe carnoso acessorio, em Mustelidios e no mangusto, proveniente do pilar esquerdo, o qual cruza dorsalmente o feixe que o pilar envia à esquerda, indo colocar-se na face torácica do pilar direito, onde se mantém distante do f.oe. Descreve em separado a disposição do delfimi neste a pars I u mbalis apresenta seus feixes carnosos limitantes o f.oe. reunidos num rafe mediano que da convexidade do arco tendíneo aórtico vai até o f.oe.. Ciceri (1932) em alguns Mamíferos confirma os achados de Bertelli mas viu no cão um f.oe. limitado só pelo pilar direito.

Dentre os Tratadistas, dispensando-me da citação dos de Anatomia Veterinária aliás examinados por Körner - citarei Owen (1868) que considera para os Mamíferos em geral, presente um cruzamento dos dois pilares ao nível do f.oe., e Nishi (1938) que diz ser o f.oe. formado pelo pilar direito, citando as observações de Körner. 
A literatura acima resumida muito embora abrangendo, creio eu, o essencial no que mais especialmente viso nestas minhas pesquisas, por certo não é e não póde ser completa; isto, tanto devido ao fáto de ser sempre difícil conseguir bibliografia sobre anatomia comparativa em nosso meio, como tambem porquê a busca e a seleção bibliográfica são dificultadas por haver AA. que estudando a anatomia de um ou outro exemplar de Mamífero não doméstico, naturalmente não podem indicar já no titulo, si sua dissecção alcançou o diafragma. Muitas vezes, por outro lado, êste músculo é citado no texto mas sem precisar o ponto por mim tomado em particular estudo i. é, de como se comportam os pilares ao nível do f.oe..

Com essa ressalva, posso citar ainda: Sperino (1897) na "Anatomia del Cimpanzè" refere haver encontrado um f.oe. do diafragma limitado exclusivamente pelo pilar dideito. Kohlbrugge (1897) tratando de Primatas em geral diz que "Der rechte Schenkel ist stärker als der linke, sendet aber zur Umrandung des Hiatus aorticus einen Teil seiner Fazern nach links hinüber'.. - Sommer (1907) apenas diz que no chimpanzé o diafragma é semelhante ao do Homem. - Schulte (1916) descrevendo a anatomia de um feto de 8 a la e noptera borealis poucas palavras dedica á constituição do f.oe.: "The bandles of the right crus are compacted into a ridge as they ascend and arch ventral of the orificium oesophagi forming a sharp muscular falx to the right and in front of the aperture. Those of the left crus continue as a plattened band upon the right reach the central tendon". A figura parece representar um f.oe. limitado em grande parte, ao menos, pelo pilar esquerdo. - Jazuta (1932) fala de f.oe. no Opos sum limitado pelos pilares mediais. - Naglieri (1933) em Myopotamus coypus apenas regista um pilar direito mais robusto que $\circ$ esquerdo, como na cobaia e no coelho. - Stewart (1936) no seu estudo sobre a musculatura dos Antropoides descreve o diafragma de chimpanzé e de orango. No primeiro os feixes musculares originados do arco do hiatus aorticus cruzam-se e limitam o f.oe.i pela figura têm-se a impressão de f.oe. limitado pelo pilar direito, com feixes originados do arco tendíneo aortico rodeando o esôfago á direita. No orango os dois pilares são unidos ao nível do hiatus aorticus, de cujo arco "strong muscle bands arose, wich at higher level encircled the esophagus (hiatus esophageus) decussating and terminating in the central tendon"

Ésses exemplos de descrições mais ou menos esporádicas do diafragma são naturalmente imprecisos, via de regra, quanto á questãa em análise. De outra parte, algumas divergências na maneira dos pilares lombares limitarem o f.oe. que aparecem entre os AA., tratadistas veterinários frequentemente (vide Körner, 1929), para a mesma espécie animal, pódem ser relacionadas com o critério não uniforme em individuar um pilar direito e um esquerdo, fáto verificável mesmo em pesquisas especiais. Haja vista, por exemplo, o trabalho de Jansen (1931): este A. descreve a diafragma da cabra com um pilar medial direito e um esquerdo limitantes do f.oe., pilares que se unem em rafe tendíneo; a aorta passaria entre o pilar lateral esquerdo e o pilar medial esquerdo. Ora, segundo Körner, o f.oe. na cabra passa num pilar medial direito, peniforme, muito mais robusto que o esquerdo; entre ambos os pilares mediais, passa a aorta

Sumariando, póde-se dizer que as pesquisas especiais sistemáticas demonstram haver em quasi todos os Mamíferos um f.oe. do diafragma limitado exclusivamente pelo pilar direito. Fazem exceção espécies de peculiar construção corpórea relacionada ao particular modo de vida (Mamíferos de vida aquática) que apresentam feixes cruzados dos pilares ou fusão dos feixes carnosos (Chiroptera): afastam-se ainda mais do plano anatomico fundamental de constituição do f.oe., algumas espécies de Xenarthra: entre êstes ha exemplos de f.oe. limitado por feixes cruzados de ambos os pilares ou de 
canal comum aórtico-esofágico ou, ainda, de um f.oe. limitado pelo pilar esquerdo. Para algumas destas espécies porém, as observações registadas são em pequeno número, donde a necessidade de exame em série suficiente. Foi com êste desejo e para trazer uma contribuição relativa a espécies ainda não estudadas, que me propuz realizar as pesquisas presentes cujos resultados são dados a seguir.

Emfim, para a espécie humana, o f.oe. é delimitado, como um caráter anatómico habitual porquê mais frequente, sômente pelo pilar medial direito nos grupos da chamada raça branca, ao passo que para os negros brasileiros a disposição mais frequente seria de um f.oe. formado por feixes cruzados áos dois pilares mediais (vide Locchi, l.c.).

\section{OBSERVAÇÕES}

material examinado compreende:

MARSUPIALIA

Didelphys aurita Wied.

Marmosa murina L.

XENARTHRA

Choloepus didactylus L. Myrmecophaga jubata L. Tamandua tetradactyla $L$. Cyclopes didactylus L.

Dasypus novemcinctus $L$.

Euphractes sexcinctus L.

Cabassus unicinctus $L$.

\section{CHIROPTERA}

Desmodus rufus Pr. Neuw.

\section{UNGULATA-ARTIODACTYLA}

Mazama simplicicornis Illi.
N. ${ }^{\circ}$

- 6 (4 fem., 2 ?)

- 3 (1 mascul., I fem., I ?)

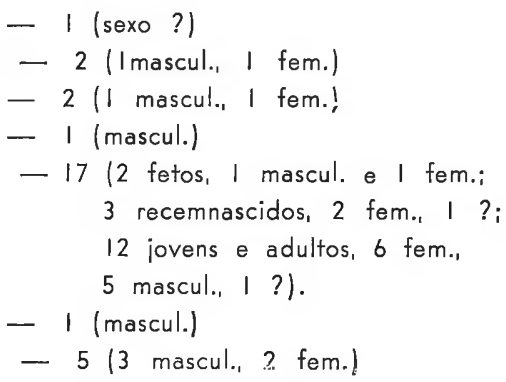

\section{CARNIVORA}

Nasua narica (L.)

Tayra barbara (L.)

Conepatus vittatus (Desm.)

- 5 (1 mascul., 4 fem.)

- 2 (I mascul., I fem.)

- 2 (mascul.)

Canis thous L.

- 4 (2 mascul., I fem., I ?)

Felis pardalis L.

- 2 (l mascul., I fem.)

Felis tigrina Schrb.

- 3 (fem.)

Procyon cancrivorus brasiliensis $v$. Iher -3 (I mascul., 2 fem.) 
RODENTIA

Agouti paca (L.)

Coendou villosus (Cuv.)

Myocastor coypus Mo.

Cavia aperea Erxl.

Dasyprocta aguti L.

Hydrochoerus capybara L.
- 4 (3 mascul., I fem.)

- 4 (2 mascul., 2 fem.)

- 4 (2 fem., 2 ?)

- 1 (sexo ?)

- 2 (mascul.)

- 3 (fem.)

\section{PRIMATES}

Hapale jacchus (L.)

Saimiris sciurea L.

Cebus sp.

Cebus cirrifer Geoffr.

Alouatta fusca (Geoffr.)

Alouatta belzebul L.
- I (mascul.)

- 2 (I mascul., I ?)

-.. 7 (5 mascul., I fem. e I ?)

- 3 (2 fem., I ?)

- 6 (mascul.)

- I (mascul.)

Em grande parte os 101 diafragmas, quasi todos de animais adultos foram dissecados após seç̧ão ao longo de suas inserções, conservadas as partes diafragmáticas do esôfago e da aorta. Em poucos casos, especialmente de Xenarthra procedí à dissecção in situ. Dêste modo, a observação é bem limitada ao comportamento dos pilares na formação do f.oe., deixando de lado as suas inserções e relações com a aorta. A dissecção era feita, quando necessário, sob uma lupa, dissociando os feixes musculares nas duas faces do músculo; daí, os esquemas mostrarem os pilares um tanto separados, para exáta indicação do jogo de seus feixes carnosos ao redor do esôfago. Ao terminar cada dissecção fazia um desenho provisório correspondente a cada face do diafragma. Não me sendo possivel reproduzir figuras do diafragma de todas as espécies examinadas, o que seria mais instructivo, apresento uma ilustração mais reduzida, escolhendo os casos que julguei interessantes, nas várias Ordens de Mamíferos. Os desenhos definitivos, que foram feitos pela Sra. L. Ebstein, representam, quasi todos, as duas faces do diafragma ao nível do f.oe. Não só porque tive uma série maior de casos de $D$ novemcinctus mas também porquê nesta espécie a limitação do f.oe. é, como caráter certamente próprio, diversa da dos idemais Mamíferos estudados, o número de figuras respectivas é maior.

O material está conservado no Departamento de Anatomia.

Ao Prof. P. Sawaya agradeço vivamente não apenas a gentileza da oferta de grande parte do material como a da determinação das várias espécies. 
Ao passar agora a dar os resultados pessoais procurarei sintetisar as descrições ressaltando apenas as modalidades de conformação que merecerem destaque, quer por se distinguirem da disposição habitual dos Mamíferos em geral ou dos diversos grupos da mesma Ordem, quer porquê representam muito provavelmente observações primeiras sobre o assunto.

Em face do valôr secundário, não tomarei em particular consideração a eventual contribuição do centro tendineo á delimitação do f.oe., pelo que a expressão usada de um f.oe. limitado exclusivamente ou não por êste ou aquele pilar, ou por ambos, refere-se á porção carnosa principal (ou total) do contorno do mesmo f.oe..

\section{Marsupialia}

Nos 6 indivíduos de Didelphys a urita, a não ser pequenas diferenças secundárias individuais, a disposição do f.oe. é, pode-se dizer, sempre a mesma. O pilar direito, bem mais robusto que o esquerdo aparece pe-

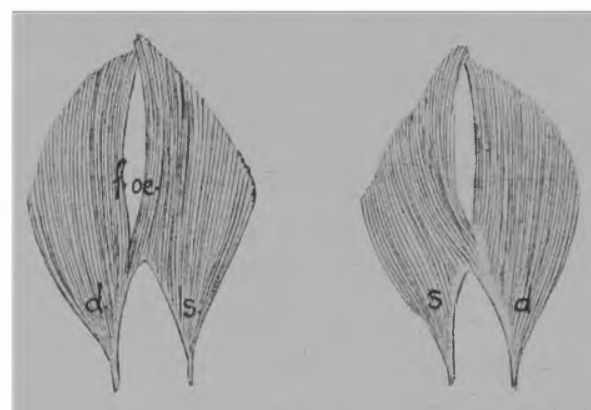

Fig. I

Marmosa murina, fem., adulta. Esquema da pars lumbalis do diafragma. F. oe., foramen oesophagicum delimitado exclusi= vamente pelo pilar direito: $d$, pilar direito; $s$, pilar esquerdo. $A^{\prime}$ esquerda, de quem observa, é a face veritrál, á direita é a face dorsal; esta disposiç̧ão se repete nas demais figuras duplas. niforme, seus feixes carnosos sendo reunidos num tendão que alcança, quasi sempre, o ângulo caudal do f.oe., tendão bem visível na face ventral do músculo. Pela marcada diferença do volume entre pilares antímeros e não muito largo f.oe., é, correspondentemente, larga a lâmina carnosa interposta entre o f.oe. e hiatus aorticus, lâmina que, originada do pilar direito, vai rodear o esôfago pela esquerda, deixando-o muito distante dos feixes do pilar esquerdo. Logo, só o pilar direito limita o f.oe.. No ângulo. cranial do f.oe. os feixes das suas. margens, direita e esquerda, ou se juxtapõem ou se superpõem antes de atingirem o centro tendíneo, o qual assim não contribue à formação do f.oe..

Em Marmosa murina (Fig. I) o f.oe. tambem é constituido sòmente pelo pilar direito, de robustez um tanto maior que o esquerdo. $O$ f.oe. é em fenda alongada, sendo relativamente fraco o feixe do pilar direito que passa para a esquerda entre o esôfago e a aorta. Na face dor- 
sal é nítido um delgado tendão laminar do pilar direito que se prolonga até a comissura caudal do f.oe.. Na outra comissura, a cranial, ha uma ligeira superposição de feixes carnosos, o que não permite participação do centro tendíneo ne delimitação do f.oe..

\section{Xenarthra}

Bradypodidae - Infelizmente, o exemplar único de Choloepus didactylus que conseguí não me chegou às mãos em boas condições, devido ao que não me é possivel dizer da anatomia da pars l u mbalis toda do diafragma. Posso porém afirmar que nêsse caso havia um orifício

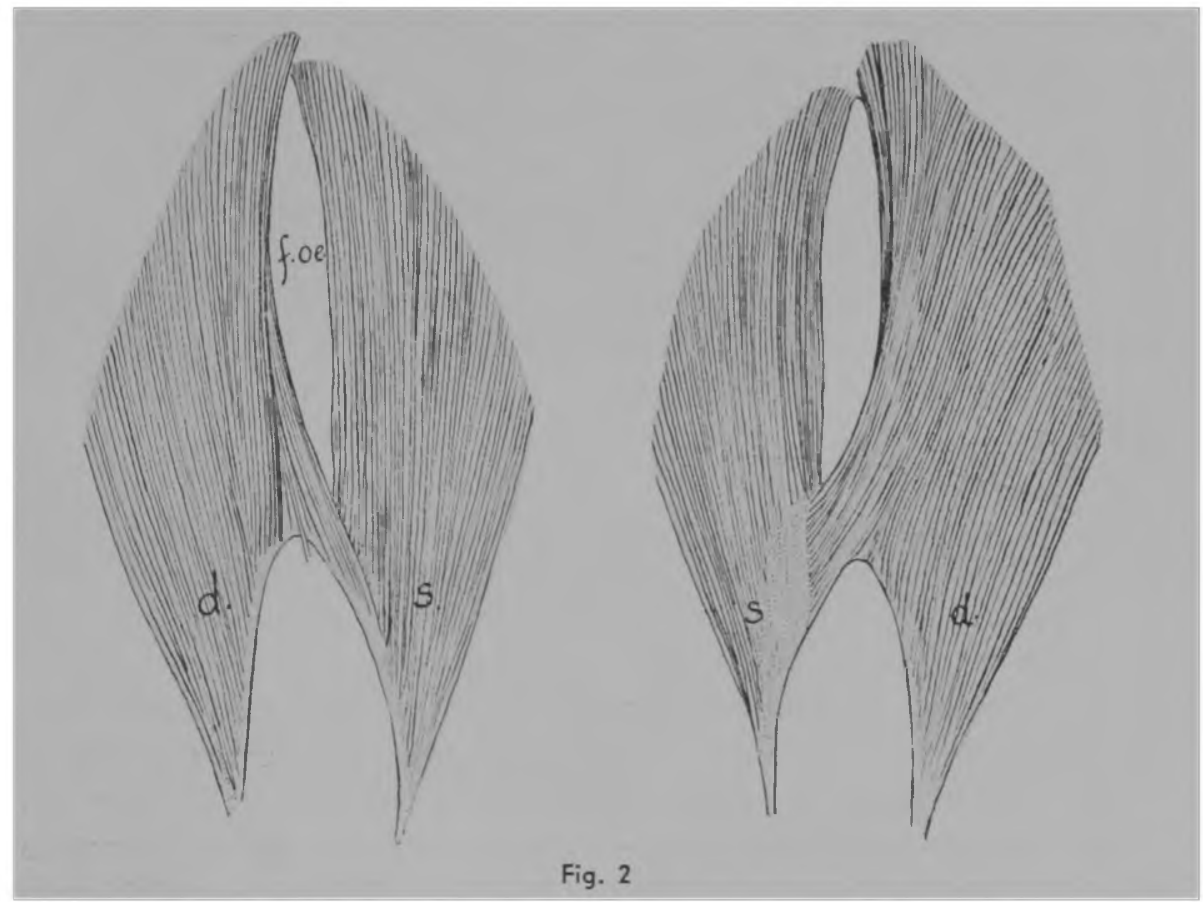

Tamandua tetradactyla, mascul., ad. - Foramen oesophagicum formado quasi exclusivamente pelo pilar esquerdo; contribuição do pilar direito ha sómente na metade cranial do contorno direito do f. oe. - Outras indicações como na fig. I.

único para a aorta e o esôfago: nada sei da disposição dos feixes caudalmente aos dois órgãos, porquê essa zona se achava já alterada ao proceder à dissecção.

Myrmecophagidae - Também para o único indivíduo de $C_{y}$ clopes didactylus vale o que acima disse; as inserções da pars 
I u mbalis não estavam perfeitamente conservadas. Assim sendo, sòmente permitiu-me a peça verificar, sem dúvida, a existência de um f.oe. separado do hiatus aorticus $O$ pilar direito desdobra-se para envolver o esôfago pela sua direita e sua esquerda, não sendo fraco o feixe que forma a margem esquerda do f.oe.. Ao nível do ângulo cranial dêste, ha uma lâmina fibrosa. continuação dos feixes carnosos das margens do f.oe.; além disso, uma pequena parte do centro tendíneo limita esse ângulo. As condições do pilar esquerdo na sua inserção impedem-me referir si havia ou não qualquer contribuição dêle, com feixes cruzados, para a formação do f.oe.; e os seus feixes mediais confundem-se com os cruzados do pilar direito.

Os dois casos de Tamandua tetradactyla estavam em boas condições de exame; num deles dissequei o diafragma in situ e no outro, depois de isolado. Em ambos a disposição é a mesma. Ao primeiro exame pela face ventral, e pela observação da zona de inserção dos pilares, parece ser ligeiramente mais forte o direito; considerando-se porém a totalidade de feixes carnosos que se prendem à esquerda, constituindo o pilar esquerdo, êste parece dominar. $\bigcirc$ fáto realmente interessante, encontrado em ambos os exemplares, bem patente na figura de um dêles (fig. 2) é ser o f.oe limitado quasi exclusivamente pelo pilar esquerdo. Si na face ventral ainda poderia haver dúvidas ou motivos de discussão a respeito (o que a meu ver não é aceitávell já na face dorsal da pars lumbalis é tão nítida a disposição de um pilar esquerdo limitando o f.oe. que dispensa mais palavras. Ao envez de um pilar direito desdobrado envolver o esôfago, como na generalidade dos Mamíferos, nos dois casos de Tamanduá mirim é o pilar esquerdo que assim se comportai e como para muitos casos de f.oe. limitado pelo pilar direito, do qual os feixes cruzados se confundem com os do pilar esquerdo, á esquerda do esôfago, aqui o feixe cruzado com origem no pilar esquerdo, ao atingir o lado direito do esôfago, une-se aos feixes mediais do pilar dêsse lado e com êle forma o contorno direito do f.oe.i mais propriamente, a contribuição do pilar direito aparece ao nível da metade cranial da margem direita do mesmo f.oe., fáto constatado nos dois casos por mim dissecados.

A rápida descrição que se segue para a espécie Myrmecophaga iubata se aplica aos dois indivíduos dissecados. Ha, em ambos, um foramen comum para o esôfago e a aorta (fig. 3) cujas margens são formadas pelos respectivos pilares direito e esquerdo, que assim se conservam separados em toda a extensão. A passagem dos dois órgãos se dá muito obliquamente entre os dois pilares, que limitam uma fenda alongada que vai das suas inserções vertebrais ao centro frênico; êste não contribue a essa 
delimitação por haver encontro e ligeira superposição dos feixes musculares ao nível do ângulo cranial do foramen comum esôfago-aórtico, o seu ângulo caudal sendo como que aberto. Examinando-se a face dorsal da pars lumbalis nota-se que cada pilar se insere por dois feixes principais,

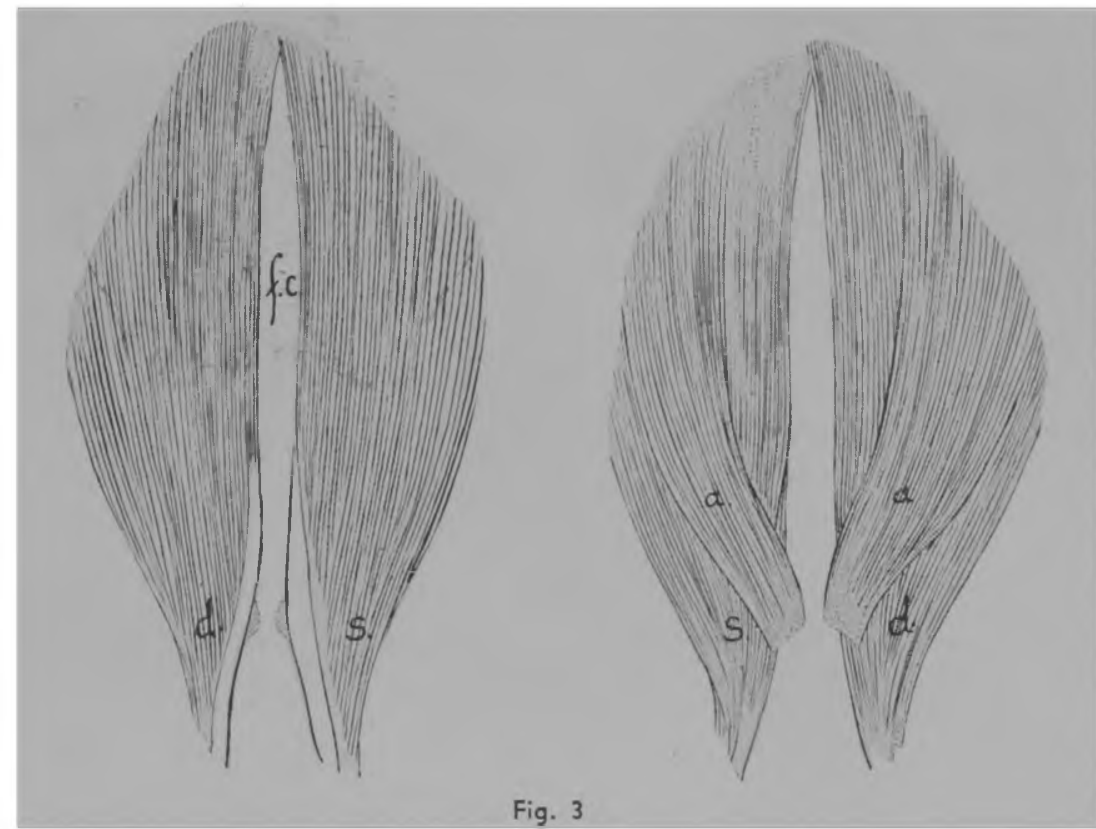

Myrmecophaga jubata, fem., adulta. - Orifício comum (f. c.) de passagem do esôfago e aorta, limitado pelos dois pilares, que se mantêm separados. a, feixes musculares um tanto isolados dos restantes de cada pilar, convergentes para a linha mediana, dorsalmente á aorta.

um cranial e outro caudal, êste por um tendão mais longo. O feixe cranial de cada lado (fig. 3, a) converge para seu antímero, sem atingí-lo; entre ambos ha porém um sistema de feixes tendíneos em lâmina transversal unindo as margens mediais das porções craniais antímeras (não representado na figura), sistema retroaortico que fecha em parte, atraz, o orifício ou curto canal comum aórtico-esofágico, disposição aliás já conhecida em outras espécies, para o hiatus aorticus. Os dois pilares são de robustez sensivelmente igual.

Dasypodidae - A disseç̧ão de 1 caso de E. sexcinctus confirmou o que regitei em nota precedente (1934) nasta espécie: o esôfago passa numa botoeira do pilar esquerdo, o qual, pela face ventral, parece ser o único a formar o f.oe.; pela face dorsal, aparece um feixe com origem do pilar direito que cruza para a esquerda, onde se une aos feixes do pilar direito, junto á margem do f.oe. Este fascículo do pilar direito, de situação dorsal, 
si bem que não constitua propriamente a margem do f.oe., concorre para limitar seu ângulo caudal, bem como ao nível do ângulo cranial tende a aproximar-se da margem, pelo que, pode-se dizer, reforça também aí, em

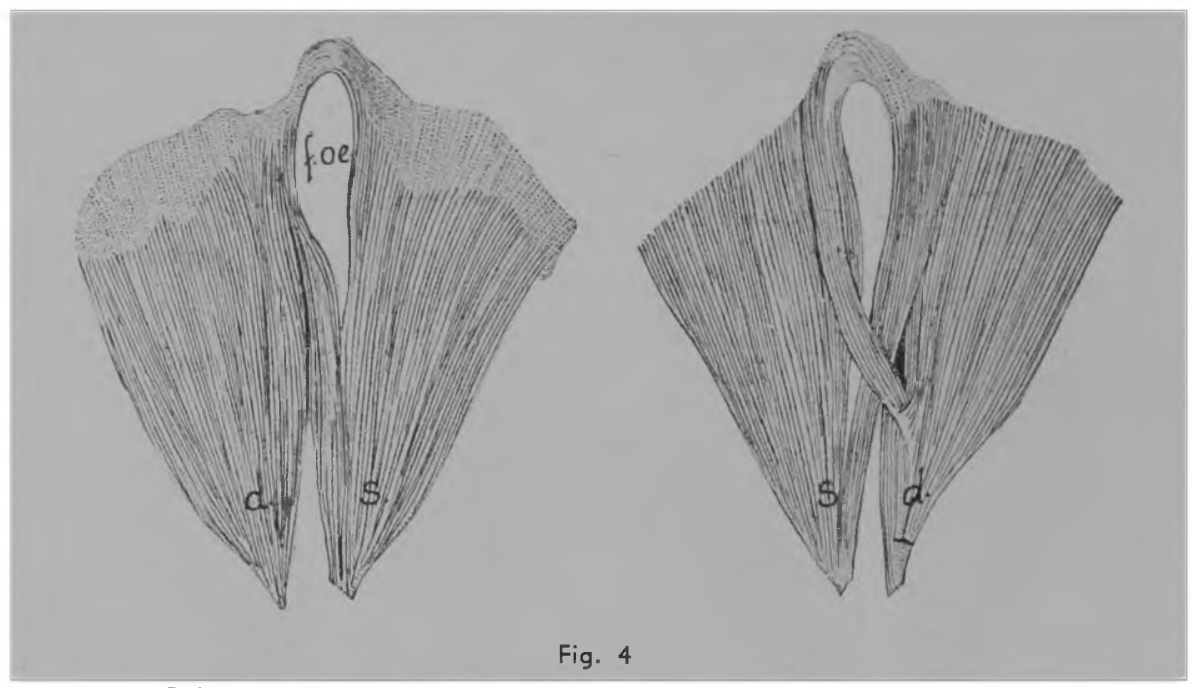

Cabassus unicinctus, fem., adulta. - F. oe. formado essencialmente pelo pilar esquerdo. Na face dorsal ha um feixe do pilar direito que cruza para a esquerda, contribuindo para limitar, em parte, o f.oe. nesse lado.

pequena extensão, o f.oe. na sua entrada. Como os feixes carnosos do pilar esquerdo que limitam o f.oe. á direita passam á tendão antes daqueles que o limitam à esquerda, uma pequena porção do f.oe. é de margem tendínea, acrescida de mínima porção do centro frênico, prolongado em uma interseç̧ão, entre feixes carnosos antímeros ao nível do ângulo cranial do mesmo. O pilar direito é um pouco mais forte que o esquerdo.

A mesma disposição, essencialmente, observei em C. unicinctus (fig. 4). Ainda o f.oe. é limitado sòmente pelo pilar esquerdo, quando se examina pela face ventral, existindo um feixe, dorsalmente, do pilar direito, mais forte que o seu correspondente do E. sexcinctus o qual cruza para a esquerda auxiliando a fechar o ângulo caudal do f.oe., e se une ao pilar esquerdo, ao nível da metade esquerda da entrada do mesmo f.oe. A robustez dos pilares é mais ou menos igual. A zona do ângulo cranial era, também aqui, de constituição fibrosa. Em 3 casos a disposição era essa, logo, repetia a verificada no indivíduo desta espécie dissecado anteriormente (1934). No outro exemplar a face dorsal da pars lumbalis mostrava mais um feixe cruzado (fig. 5): quer dizer, além do feixe dorsal, homólogo ao dos demais casos, que o pilar direito envia à esquerda, onde se mistura 
com os feixes do pilar esquerdo, que limitam aí a margem do f.oe., mais um feixesinho é evidenciável, delgado, que, originado do pilar esquerdo supracitado vai confundir-se com os feixes do pilar direito, junto à união deste como o pilar esquerdo, bem distante da margem esquerda do f.oe.. Ha pois, um f.oe. constituido pelo pilar esquerdo principalmente, mas para o mesmo

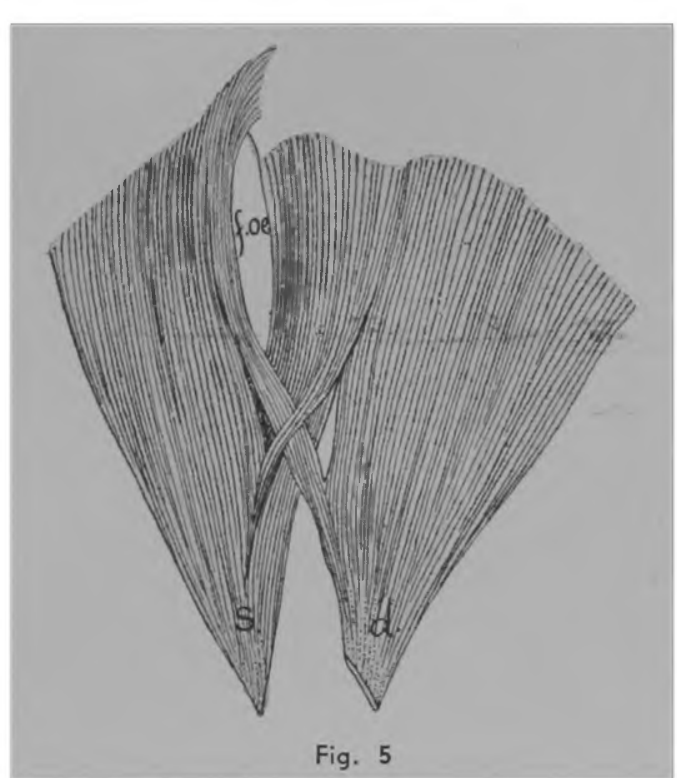

Cabassus unicinctus, fem., adulta. - Superficie dorsal da pars lumbalis mostrando um duplo cruzamento de feixes dos dois pilares. O f. oe. é semelhante ao do caso da fig. precedente. O feixe accessorio do pilar esquerdo, cruzado para a direita, não limita a f. oe. concorre um feixe do pilar direito, dorsal, o qual fecha o seu ângulo caudal como também contribue na formação da margem esquerda do f.oe., em maior extensão do que faz seu homólogo, na maioria dos casos estudados; além disso, existe um feixe accessório, não limitante o f.oe., cruzado dorsalmente, com origem do pilar esquerdo, no conjunto havendo um duplo cruzamento de feixes dos dois pilares.

Também para o $D$ a sy pus novemcinctus posso confirmar o meu primeiro achado de 1934. Em todos os 17 exemplares, sem exceção alguma o f.os. se apresenta limitado sòmente pelo pilar esquerdo, (figs. 6 e 7) tal como nos 6 exemplares da minha nota prévia. Nesta nova série observei apenas ligeiras variações quanto à robustez do feixe que, vindo do pilar esquerdo, limita o f.oe. à direita, sendo por conseguinte maior ou menor a separação entre o esôfago e a aorta; do mesmo modo, a zona tendínea dêsse feixe do pilar esquerdo era mais ou menos extensa, donde um f.oe. com margem tendínea em maior ou menor extensão (figs. 6 e 7). Nos casos em que o feixe interposto entre aorta e esôfago era mais largo, correspondentemente o pilar esquerdo é igual ou maior, em volume, que o direito; na generalidade dos casos, parece ser o pilar direito ligeiramente mais robusto que o esquerdo. A exata avaliação porém a respeito, só seria possível por meios mais precisos que a simples vista. Mesmo nos casos em que o pilar direito em parte se superpunha ao esquerdo, nas suas margens, jamais notei contribuição daquele para a formação do f.oe. propriamente. Ainda quando - feixe do pilar esquerdo situado á direita do esôfago é delgado, bem 
evidente é a sua inserção á esquerda da linha mediana, juntamente aos demais feixes dêsse pilar (fig. 8). O ângulo caudal é naturalmente delimitado pelo desdobramento do pilar esquerdo; o cranial, em parte é fibroso á custa

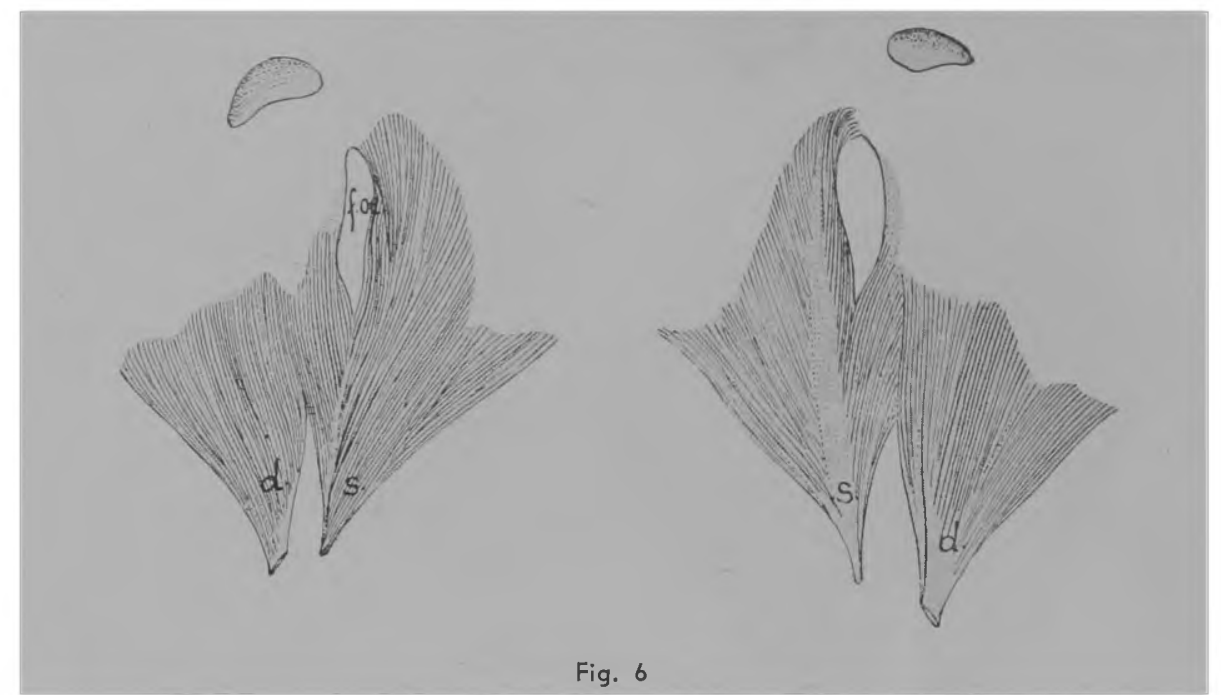

Fig. 6

Dasypus novencinctus, fem. adulta. - F. oe. delimitado exclusivamente pelo pilar esquerdo. Forte a porção do pilar esquerdo que separa o esôfago da aorta e limita o f. oe. á direita. Zona fibrosa do f. oe., extensa.

da zona tendínea do pilar, e, de uma intersecção fibrosa variavel em extensão e zona correspondente do centro frênico, com o qual aquela se continua constituindo-se, mais que um simples orifício, um curto canal esofágico Enfim, ainda variou ligeiramente, a espessura e comprimento do tendão do. pilar esquerdo, do qual partem os feixes carnosos limitantes do f.oe.. Pela face ventral, apresentava-se um fino tendão, que alcançava, geralmente, o. ângulo caudal do f.oe., ao passo que na outra face percebe-se uma lâmina mais ou menos larga, tendínea, delgada, de cujas margens e face ventral partem os feixes carnosos que rodeiam o esôfago, com variantes como das figs. 6 e 7 relacionadas com a diferente robustez do feixe muscular que limita o f.oe. á direita.

\section{Chiroptera}

Para os casos de Desmodus rufus a descrição será muito rápida por não se afastar, essencialmente, da disposição vista por Bertelli em. Vesperugo noctula $\mathrm{Ha}$ como que fusão dos pilares, os feixes carnosos partindo de uma longa intersecção fibrosa, fina, o conjunto lembrando. a disposição peniforme; os feixes carnosos limitam um f.oe. o qual é sepa- 
rado de um orifício para a aorta, também muscular, por um mínimo feixe carnoso de difícil demonstração; êle se interpõe aos dois órgãos e com

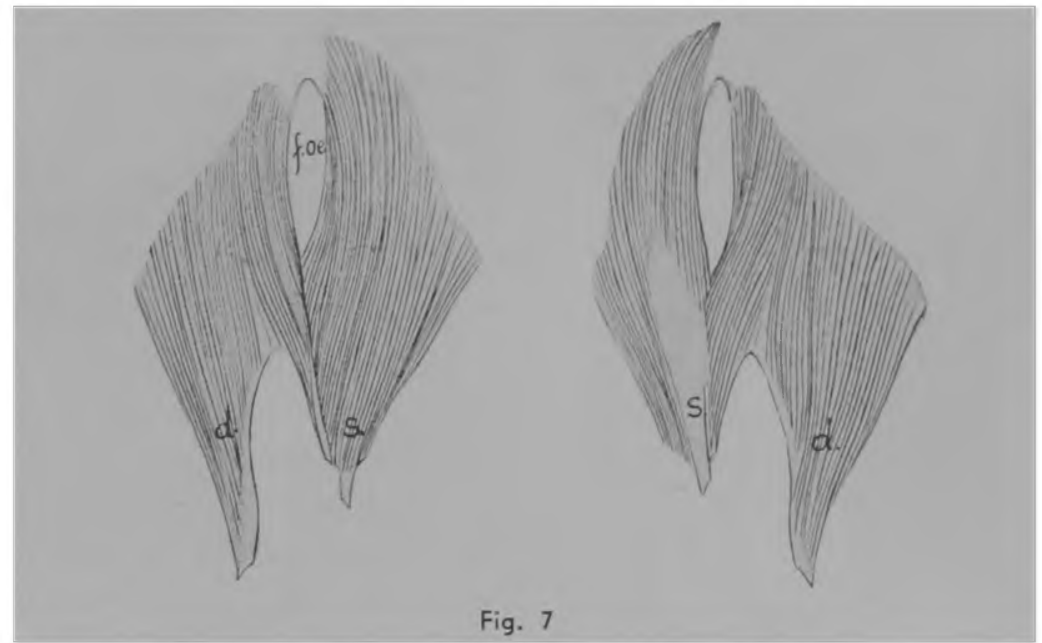

\footnotetext{
Dasypus novemcinctus, fem., adulta. - Mesma disposição que no caso da fig. 6; apenas neste é menos forte o feixe que separa o esôfago da aorta e menos extensa a zona fibrosa do f. oe.
}

lente foi seguido, notando que vai dos feixes que representariam um pilar esquerdo para a direita, rodeando o esôfago pela sua direita afim de alcançar o centro tendíneo. Este não concorre para limitiar o f.oe..

\section{Ungulata}

No feto de Mazama simplicicornis o f.oe. do diafragma é formado só pelo pilar direito, muito mais robusto que o esquerdo, êste conservando-se muito afastado da margem esquerda do mesmo f.oe.. O centro tendineo não entra na constituição do f.oe., que é de dimensões estreitas, isto é, apenas suficiente para a passagem do esôfago.

\section{Carnivora}

Os 5 exemplares de $\mathrm{N}$ asua $\mathrm{narica}$ apresentam um largo f.oe. constituido exclusivamente pelo pilar direito, mais forte que o esquerdo (fig. 9). Em todos êles os feixes carnosos se cruzam em rafe ao nível do ângulo cranial do f.oe., onde se nota em 4 casos, uma fina intersecção fibrosa entre os feixes que rodeiam o esôfago pela direita e pela esquerda. Com exceção de I caso fêmea adulta, nos demais 4 observei um fáto curioso: 
ao nível do ponto em que do tendão do pilar direito os feixes carnosos se desdobram para contornar o esôfago, ha um nódulo que, nos indivíduos

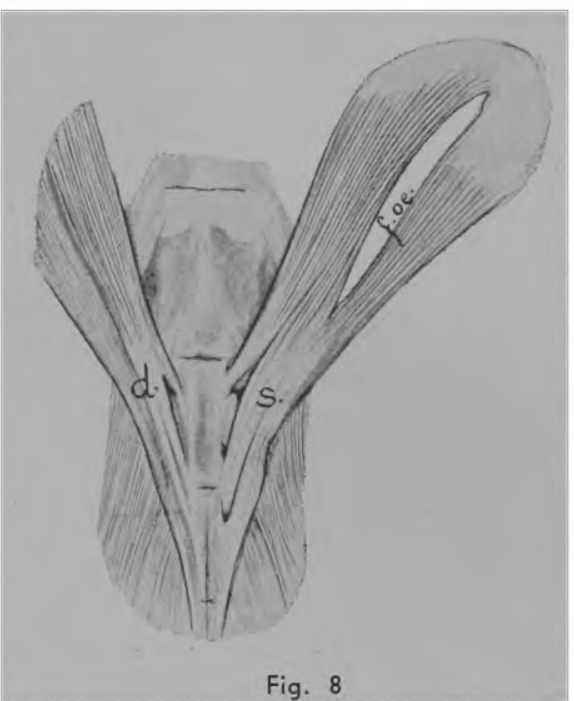

Dasypus novemcinctus, fem., adulta.

- Inserçães vertebrais dos pilares lombares adultos, já pelo raspar com uma pinça ou bisturí, dava a sensação de ser de natureza óssea. No caso da figura, feito o exame histológico, êste demonstrou porém tratar-se de cartilagem hialina. Bertelli no E. europaeus encontrou 4 vezes sobre 6 um ossículo sesamoide em semelhante situação.

\section{Em Procyon cancrivorus} brasiliensis f.oe. em larga fenda, limitado sòmente pelo pilar direito, mais forte que o esquerdo. O centro frênico não concorre, ou apenas em mínima parte num caso, para a formação do f.oe..

Nos casos de Felis tigrina ha um amplo f.oe. formado pelo pilar direito, mais robusto que o esquerdo. No ângulo cranial do f.oe. os feixes musculares ou se superpõem antes de sua inserção no centro frênico, ou se unem por meio de uma intersecção fibrosa que abraça o esôfago ventralmente.

A mesma disposição notei em Felis pardalis; f.oe. formado pelo pilar direito, mais forte que o esquerdo, com alça muscular rodeando ventralmente o esôfago, ao nível do ângulo cranial.

A disposição em Canis thous repetia, em essência, aquela das duas últimas espécies citadas quanto à constituição do f.oe. e á morfologia do seu ângulo cranial; num caso dentre os 4 dissecados no entanto, houve ligeira variação. Pela face ventral, parecia que o f.oe. era limitado pelos dois pilares, cada um mantendo-se do seu lado, partidos de um forte arco tendíneo do hiatus aorticus; na face dorsal porém, via-se claramente que a origem dos feixes carnosos que limitavam o f.oe. era toda ela á direita, logo, o pilar direito formava, só êle, o f.oe..

Repete-se ainda a mesma morfologia do f.oe., em Tayra barbara e Conepatus vittatus (fig. 10); em ambas as espécies ha um f.oe. limitado sòmente pelo pilar direito, mais forte que o esquerdo. O feixe do pilar direito que contorna o esôfago pela esquerda é delgado, o orifício é amplo e no seu ângulo cranial ha cruzamento de feixes musculares, em alça prèesofágica mais evidente em Conepatus vittatus Devo notar, po- 
rém, que num dos exemplares desta espécie, o delgado feixe do pilar direito que deveria limitar o f.oe. á esquerda, não o faz em toda a extensão da margem esquerda do f.oe. porquê se coloca dorsalmente aos feixes mediais do

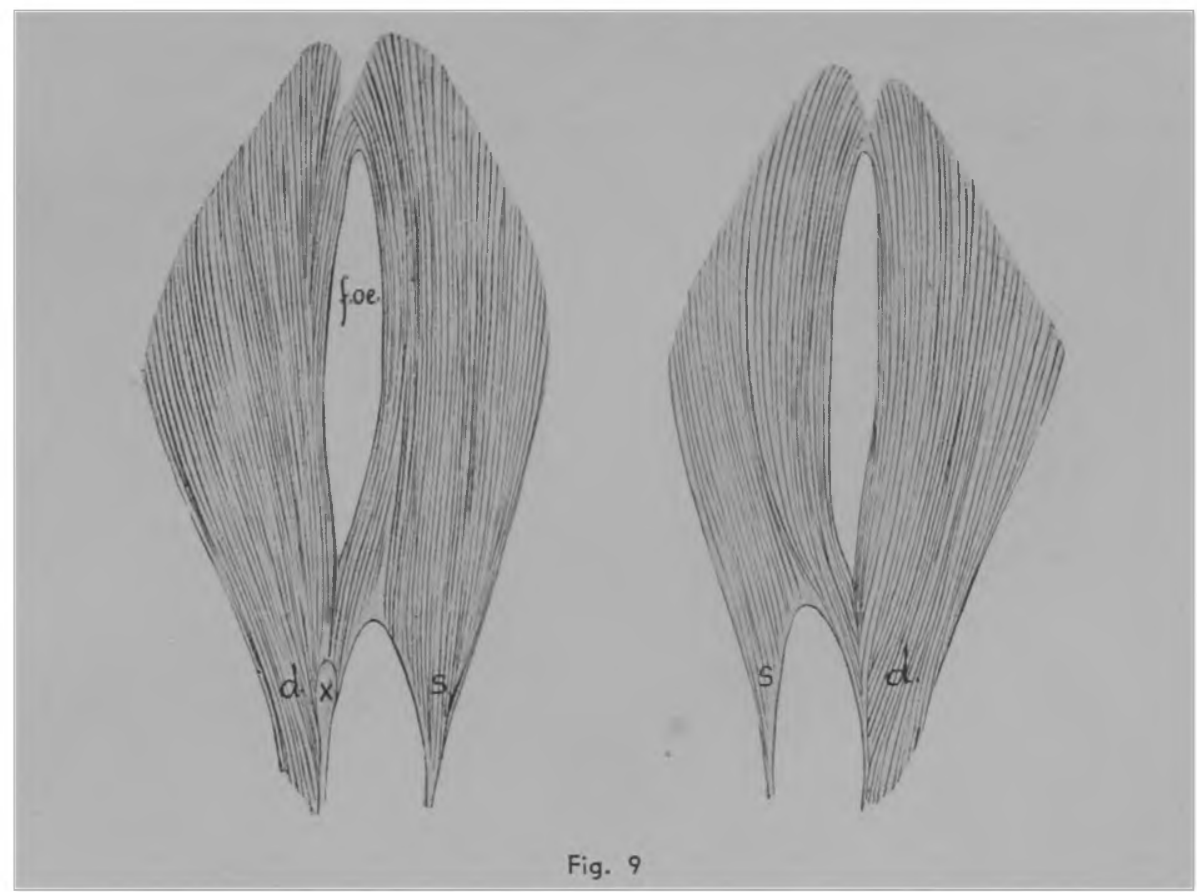

Nasua narica, fem., adulta. - Na extremidade cranial do tendão do pilar direito ha um nodulo cartilagineo $(X)$.

pilar esquerdo; donde ser o f.oe., na metade de sua margem esquerda, formado por feixes do pilar esquerdo; trata-se, bem parece, de uma simples e secundária variação.

\section{Rodentia}

O f.oe. em Hydrochoerus capybara depende exclusivamente do pilar direito (fig. II) muito mais robusto que o esquerdo; os feixes carnosos partem de um forte tendão, para limitar o amplo f.oe., cujo ângulo cranial corresponde ao centro frênico. Num caso (fêmea jovem) a presença de um rafe fibroso no pilar esqueráo dificultava dizer-se, de pronto e pela vista ventral, qual o pilar que limita o f.oe.; o exame pela face dorsal tirava a dúvida. 
A conformação do f.oe. em Cavia aperea e Dasyprocta a guti não difere; só o pilar direito o limita, pilar que predomina em robustez; ângulo cranial do f.oe. limitado pelo centro tendíneo, em maior extensão na primeira espécie.

Repete-se a constituição de um f.oe. à custa exclusiva do pilar direito, mais forte, em Agouti paca e Coendou villosus com pequena contribuição do centro frênico na altura do ângulo craniali geralmente é

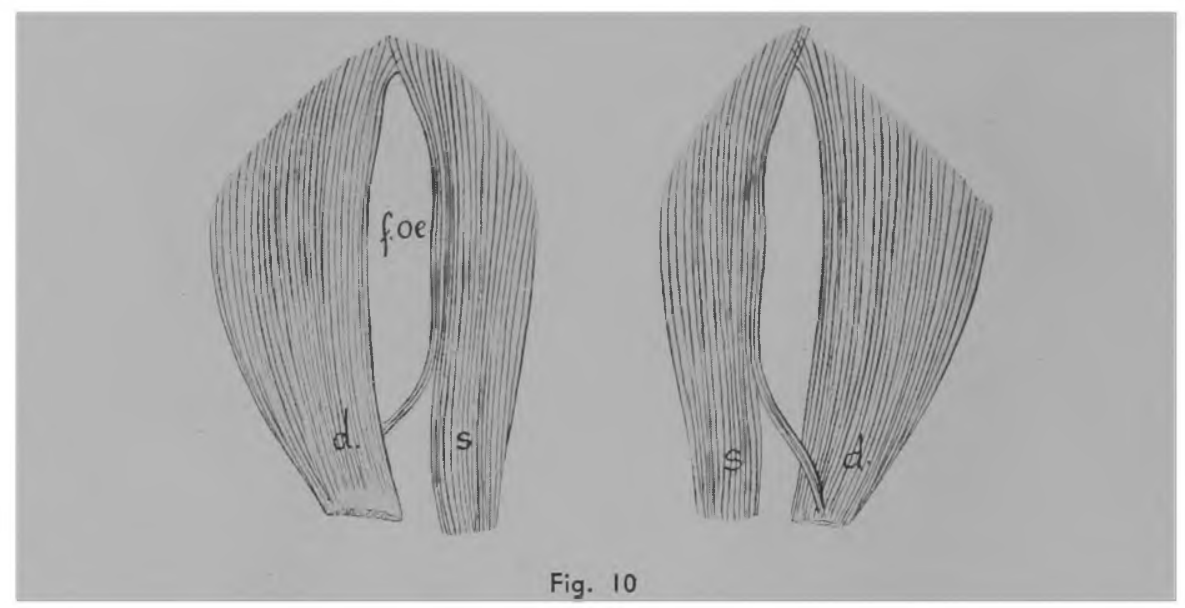

Conepatus vittatus, mascul., adulto. - $F$ oe. formado pelo pilar direito; o feixe que constitue a margem esquerda do f. oe. é muito delgado.

forte o feixe que separa a aorta do esôfago, por conseguinte, bem patente a diferença de volume entre os dois pilares. Uma variedade observei num dos casos de C. villos us: na face dorsal ha passagem de feixes carnosos. transversais, da direita para a esquerda, na zona interaórtico-esofágica.

Ainda f.oe. limitado só por mais forte pilar direito, em M yo c a s tor coypus (fig. 12) o centro frênico em pequena parcela concorrendo para fechar o ângulo cranial, onde uma curta lâmina fibrosa envolve ventralmente. o esôfago, dando inserção a alguns feixes das margens do f.oe. A dissecção. de dois casos in situ demonstrou haver reunião dos feixes dos dois pilares, atraz da aorta, numa espécie de tendão laminar ímpar e mediano, fechando-se assim o hiato aórtico; a mesma disposição aliás observei em casos dis... secados no animal, em $M$ murina e $A$ paca

\section{Primates}

Em Hapale jacchus (fig. 13) e Saimiris sciuria á parte " naturalmente, diferenças pequenas, ha um pilar direito mais robusto que: 
seu antímero limitando, só êle, o f.oe.. Os feixes carnosos do pilar direito originados em fino tendão cordoniforme, têm a disposição peniforme. $O$ f.oe., não amplo, não recebe contribuição do centro frênico visto os feixes carnosos se juntarem ou em pequena extensão se entrecruzarem no ângulo cranial, antes de sua inserção no centro tendíneo.

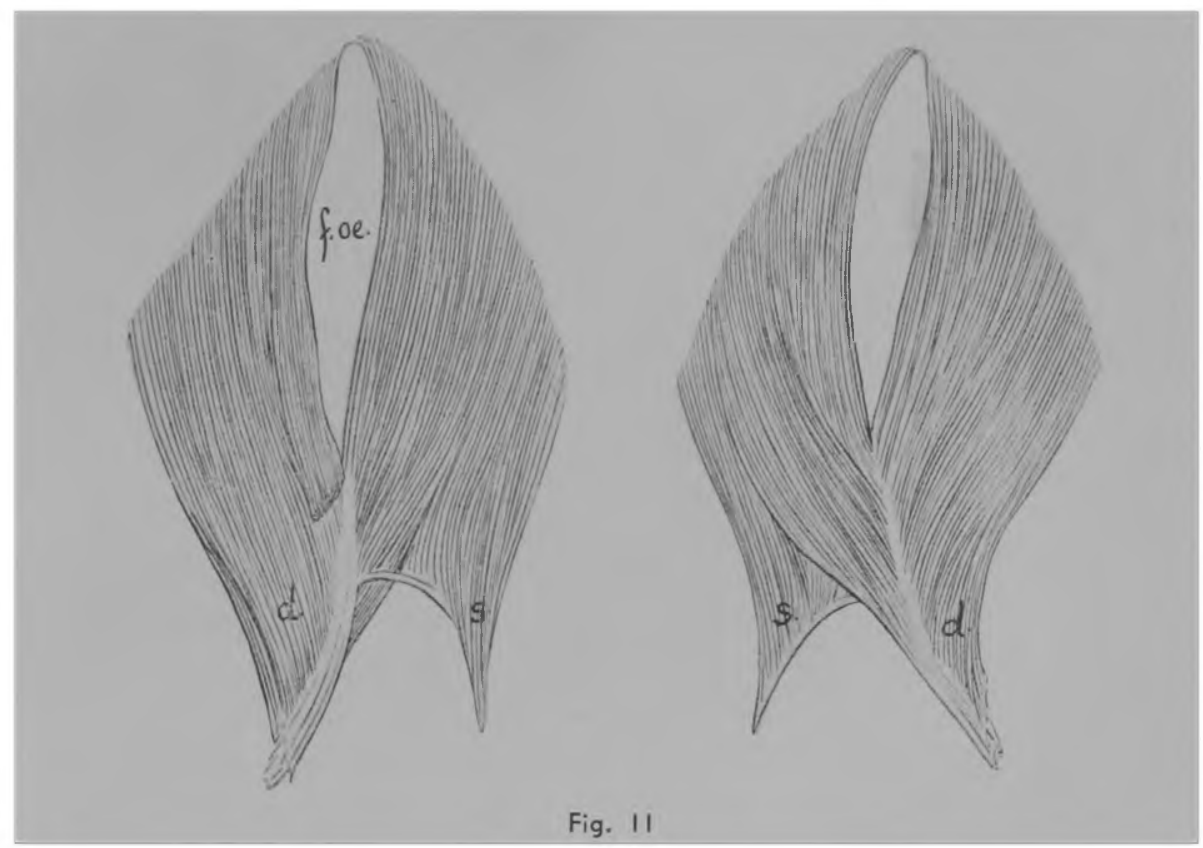

Hydrochoerus capybara, fem., odulta. - F. oe. limitado exclusivamente pelo pilar direito, muito mais robusto que 0 esquerdo.

F.oe., relativamente largo em 4, mais estreito em 3 (2 machos e I fêmea), era nos 7 casos de $\mathrm{C}$ ebus de espécie não determinada, constituido sòmente pelo pilar direito, nitidamente mais forte que o esquerdo. Os feixes do pilar direito tomam aspéto de músculo peniforme, visível na sua face ventral um tendão fino, um rafe carnoso nia face oposta. Nos casos de f.oe. mais estreito, mais larga era a lâmina muscular interaórtico-esofágica. A não ser numa observação (fêmea) com intersecção fibrosa prèesofágica no ângulo cranial, nas outras ha justaposição dos feixes das margens direita e esquerda do f.oe..

Em Cebus cirrifer f.oe. em fenda alongada do pilar direito, sempre mais forte que o pilar oposto. Tendão de formação peniforme visivel na face abdominal do pilar direito, rafe muscular, na sua face dorsal.

No ângulo cranial, juxtaposição dos feixes carnosos que assim fecham - f.oe.. Num dos exemplares ha, na face abdominal da pars lu mb a li s um 
pequeno feixe carnoso aberrante que do ângulo cranial do f.oe. se dirige para a esquerda, em $S$, confundindo-se com os feixes mais mediais do pilar esquerdo, junto aos feixes do pilar direito que limitam á esquerda o f.oe.; êsse feixe aberrante só tem relação com o f.oe. ao nível do seu ângulo cranial.

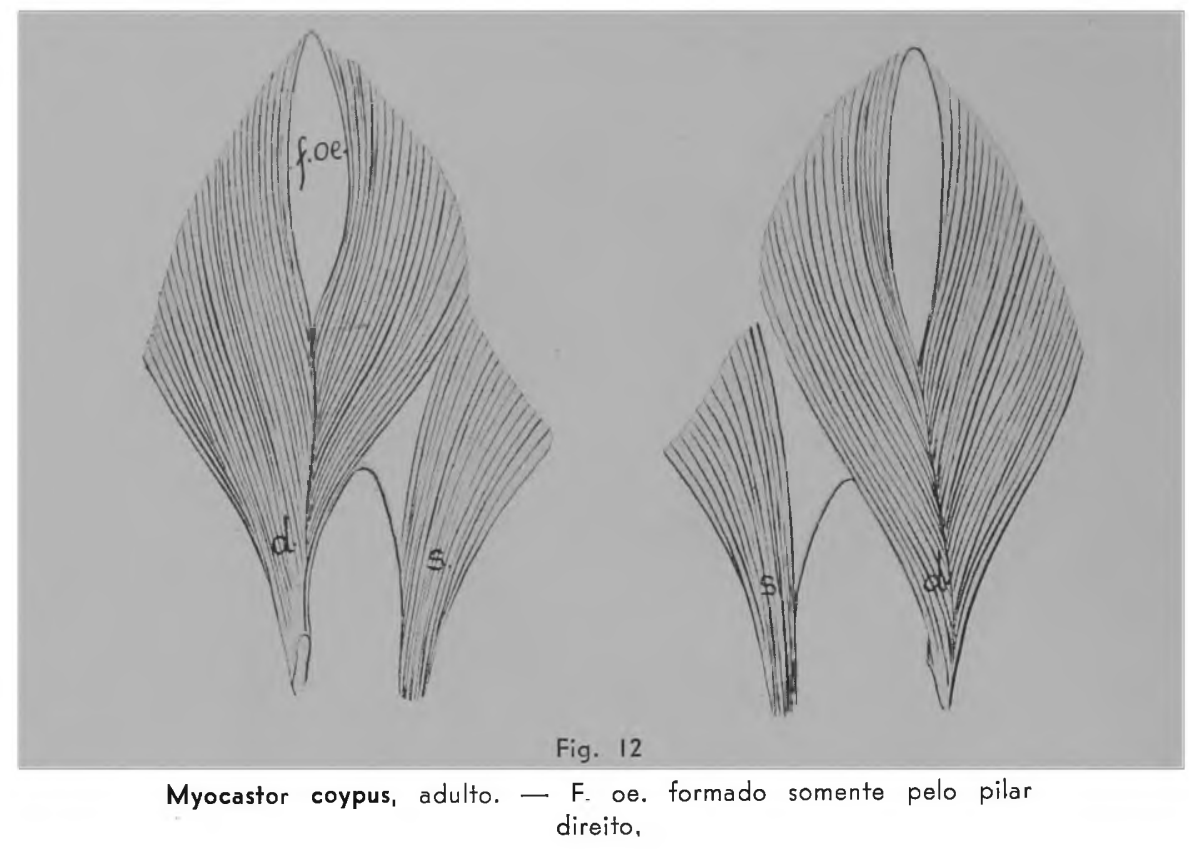

Dissecando 6 casos de Alouatta fusca é claro que me foi dado encontrar pequenas variantes; mas, no essencial, ha sempre um f.oe. limitado só por um mais forte pilar direito, originado em tendão de espessura variável, mais visível na face abdominal que na oposta. Uma vez, (macho ad.) particularmente na face torácica, vi uma bastante localizada contribuição do centro tendíneo, na altura do ângulo cranial.

Finalmente, em A belzebul (fig. 14) o pilar direito é o único limitante do f.oe., pilar que sobrepuja seu antímetro. F.oe. não amplo, com superposição de feixes no seu ângulo cıanial.

\section{COMENTÁRIOS E CONCLUSÕES}

Se bem que o material não seja uniformemente repartido pelas várias espécies, e que para algumas só conseguí um exemplar, observa-se que na maioria dos casos ha a mesma disposição fundamental: um f.oe. do diafragma limitado exclusivamente pelo pilar direito, mais robusto que seu ant.mero, 
sem qualquer contribuição do pilar esquerdo, á parte, naturalmente, a eventual contribuição do centro tendíneo. Fazem exceção as espécies de Xenarthra e Chiroptera, que apresentam um desvio daquela conformação geral. Si para as espécies representadas apenas por um indivíduo

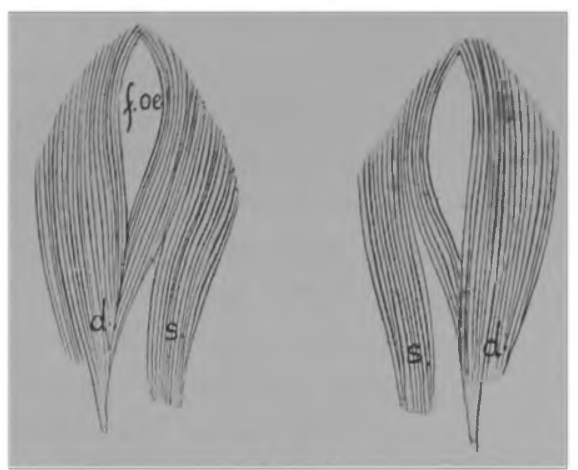

Fig. 13

Hapale jacchus, mascul., adulto. - F. oe. limitado somente pelo pilar direito. não se possa sem mais afirmar ser essa a disposição a elas correspondente, para as com alguns casos já se póde supôr, com possibilidade, ser a disposição habitual; aliás, este raciocinio, até certo ponto se aplica também ao outro grupo, visto não haver aparecido uma morfologia especial de f.oe.. mas, ao contrário, uma constituição correspondente áquela dos Mamíferos em geral.

Dentre as exceções, sobre a espécie de Chiroptera (Desmodus rufus) observada, nada ha de particular a anotar, por isso que a conformação da pars lumbalis e do f.oe. sendo semelhante a de outras espécies dessa Ordem estudados por outros AA. (Bertelli, Goldschmidt) faz crêr que seja essa a anatomia da pars l u mbal is do diafragma nos Chiraptera animais de peculiares atitudes e hábitos; e é curioso o fáto dessa morfologia se aproximar daquela da pars lumbalis do Bradypus conforme já notei em outra ocasião (1931).

Interessa mais de perto o resultado obtido nos Xenarthra Dasy pádidae muito em especial, cuja anatomia do f.oe. foi o motivo primeiro desta minha publicação: e por isso, propositadamente procurei aumentar o número de observações para tirar conclusões que possam ser consideradas como definitivas a respeito, ao menos para a espécie $D^{\prime}$ nove m cinctus Assim, além dos 6 casos dessa espécie da minha nota prévia, ha aquí a somar 17 outros da mesma espécie; e nos 23 casos eu sempre encontrei no $D$ novemcinctus um f.oe. limitado exclusivamente pelo pilar esquerdo. Sinto-me autorisado a dizer que é uma disposição, própria da espécie, senão exclusiva a ela.

Ao lado da disposição do f.oe. nesta espécie de Xe n a r thra deve ser lembrada a observada em $T$ tetradactyla: apesar de haver dissecado só 2 casos, em ambos trata-se também de um f.oe. limitado essencialmente, pelo pilar esquerdo. Körner, na sua observação de $T$ tetradactyla fica em dúvida sôbre de que pilar se origina o feixe muscular que forma a margem direita do f.oe.; julga ser do direito, si bem que pareça provir do esquerdo: 


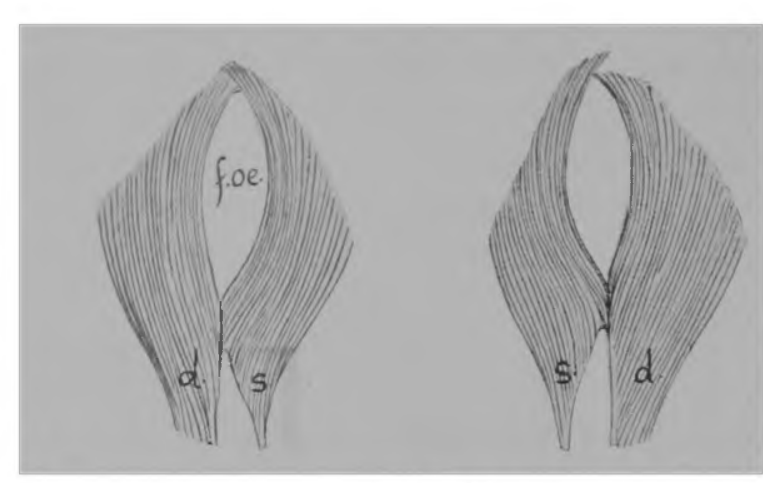

Fig. 14

Alouatta belzebu!, mascul,, adulto. - F. oe. formado somente pelo pilar direito. e, por analogia com o que se nota em outros Mamíferos e no Homem lalguns feixes do pilar direito partindo do arco do hiatus a o r ticus, à esquerda da linha medianal e também considerando o que descreve Goldschmidt na mesma espécie lum feixe que da direita para a esquerda separava o esôfago da aorta), conclue ser o f.oe. formado pelo pilar direito. E acrescenta que o seu achado poderá representar uma variedade
individual. Ora, si outras observações, mais numerosas, confirmarem o que eu encontrei, então teremos mais uma espécie entre Xenarthra - T te tradactyla - com f.oe. limitado só pelo pilar esquerdo, tal como para o $D$ novemcinctus á parte a pequena contribuição do pilar direito, neste lado do f.oe.i e consequentemente, a variedade individual" seria aplicável ao caso de Goldschmidt e não ao de Körner.

Fundamentalmente, também em C unicinctus e $E$ sexcinc tus ha um f.oe. limitado pelo pilar esquerdo. Com as ressalvas quanto ao número de casos dissecados, parece que estas duas espécies ide D a s y podidae apresentam uma importante complicação morfológica da pars lumbilis; i. é, o cruzamento de feixes antímeros ao nível do f.oe., muito embora pouco contribua um feixe do pilar direito, cruzado para a esquerda, para o fechamento do f.oe.. $\bigcirc$ cruzamento de feixes porém, é um caracter anatómico raro entre os Mamíferos, segundo as pesquisas minuciosas de Körner, só aparecendo em Pinnipedia além do que se conhece para o Homem, a êsse respeito. Na minha pequena série de $C$ unicinctus num caso (fig .5), ha cruzamento duplo, o que julgo representar, agora, uma simples variedade individual.

Mas, ainda entre Ẍenartnra a pars lumbalis do diafragma difere tipicamente da generalidade dos Mamíferos, em $M$ jubata No caso de Pouchet e nos dois meus, ha um orifício comum de passagem para - esôfago e a aorta, com as reservas mais uma vez, dependentes do pequeno número de observações existentes até hoje. Não seriam assim sòmente os representantes de Bradypodidae (Br tridactylus Ch didactylusl os portadores de um canal comum aórtico-esofágico do diafragma, pois que o mesmo se verifica em $\mathrm{M}$ iubata $\mathrm{Ha}$ 
porém uma diferença essencial; nesta última espécie o largo orifício ou canal de passagem parece representar uma fusão do hiatus a orticus com o f.oe., ou melhor, nada mais é que uma conservada separação entre os dois pilares, desde suas inserções vertebrais até suas inserções no centro tendíneo; nos casos de Bradypodidae o canal único aparece como si a aorta, deslocada ventralmente, passasse pelo f.oe., junto com o esôfago, a pars I u mbalis evidenciando uma como que fusão dos dois pilares mediais, cujos feixes limitantes do canal comum têm inserções principais à esquerda no Br. tridactylus. Por conseguinte, si em em ambos os casos ha um canal único para a aorta e o esôfago, não ha perfeita correspondência entre um tipo e outro de construção da pars lumbalis na constituição do canal de passagem dos dois órgãos.

Em síntese, nas várias espécies de Xenarthra estudadas, evidenciase uma anatomia muito especial da pars lumbalis do diafragma, a qual, até certo ponto, distingue caracteristicamente esse musculo em tais Mamíferos.

Um exame de conjunto demonstra que a morfologia da pars lum balis e a disposição do f.oe. diferem da morfologia e disposição do f.oe. consideradas habituais nos Mamíferos, precisamente em espécies, de habitos, atitudes, construção corporea muito particulares, tratando-se de Xenarthra Chiroptera e Pinnipedia Assim, que a disposição em feixes cruzados dos dois pilares, de algumas espécies, seja relacionada á forma do torax, nelas não mais em quilha ou achatado tranversalmente mas sim "ovalar transversalmente" como quer Körner, não parece haver dúvida; realmente, a seç̧ão do torax em Pinnipedia, como em Dasypus, é de figura diversa daquela da maioria dos Mamíferos, quadrúpedes. É bem verdade que o torax em Bradypodida e também tende a circular, em secção transversal, e a pars lu mbalis não segue a conformação dos acima citados. Demais, a semelhança entre f.oe. de Pinnipedia e Homem devida apenas àquela de construção do torax vale só até certo ponto, si lembrarmos que nem entre Primates, havia f.oe. como no Homem, parecendo não haver referências precisas ide casos entre êles, de cruzamento bem claro dos pilares. Isto sem tomar-se em consideração a diferente percentagem entre negros (brasileiros) e brancos, na nossa espécie, quanto á limitação do f.oe. (Locchi, I. c.). E mais, a conformação toracica diversa nos diferentes tipos constitucionais de uma dada "raça" lembra possiveis diferenças da pars l u mbalis nos tipos, no ponto aqui visalo questão, parece, ainda não estudaıla.

Não ha negar a interrelação da anatomia do diafragma em cada grupo e morfologia do tronco e dos órgãos mais diretamente relacionados com o 
diafragma, como esôfago, fígado e estômago, aorta, etc., e bem assim, vida habitual de cada espécie, interferindo na sua mecânica respiratória. Mas a analise e exáta avaliação dêsses fatores múltiplos e complexos, alguns próprios ao grupo dado, sem dúvida não é fácil; requerer, antes de mais nada, o conhecimento da anatomia em todos êsses pontos, em cada espécie e em número suficiente, com justa apreciação das respectivas proporções, ao se confrontarem espécies diversas, i. é, do seu valôr relativo além do absoluto, para uma interpretação que possa ser aceita como mais provavel ou definitiva. Consequentemente, a sistematisação do f.oe. limitado sòmente pelo pilar direito como um caráter anatómico de significado "primitivo" e si limitado pelos dois pilares, como de valôr "progressivo" valerá não com a aceitação do sentido extrito e próprio dos termos, mas apenas em se consicierando, pelo exame anátomo-comparativo do mesmo f.oe., o primeiro tipo como fundamental ou mais comumente encontrado entre Mamíferos, o segundo existindo em grupos cuja configuração torácica se afasta da geral nos Mamíferos e, mais propriamente, na espécie humana. Aliás, é bem sabido de como e quanto diferentes são as várias classificações propostas para os "caracteres morfológicos" em base da sua anatomia comparativa, e suas respectivas críticas possiveis.

Mas, deixando de lado questões de ordem interpretativa ou doutrinária mais geral, para cuja resolução os nossos conhecimentos atuais são precários, e restringindo-me ao campo puramente morfológico objetivo, concluo assinalando um fáto que principalmente se destaca das minhas pesquisas: mais uma vez o estudo anatómico de $X$ e $n$ a $r$ th $r$ a brasileiros demonstra peculiaridades próprias a este curioso grupo de Mamíferos, dentre os quais alguns são tão característicos da Fáuna neotropical.

A guisa de conclusões geraes e segundo pesquisas sistemáticas sobre o assunto, pode-se dizer que:

a) nos Mamíferos em geral o foramen oesophagicum do diafragma é delimitado exclusivamente pelo pilar direito, mais forte que o esquerdo;

b) raramente o pilar esquerdo contribue para essa delimitação ou apresenta um seu feixe cruzando para o lado direito, como em alguns grupos muito especiais de Mamíferos (em Pinnipedia em Dasypodidae). além da espécie humana;

c) um canal comum aórtico-esofágico só foi observado em algumas espécies de Bradypodidae e de Myrmecophagidae com nítidas diferenças entre as duas Famílias, na disposição dêsse canal diafragmático para o esôfago e aorta; em algumas espécies de Chiroptera a pars lumbalis dispõe-se à semelhança da de Bradypus na união dos pilares, mas com separação dos dois órgãos por feixe carnoso; 
d) no $E$ sexcinctus e em $C$ unicinctus ha feixes cruzados dos dois pilares, mas o f.oe. é essencialmente formado pelo pilar esquerdo. No Tamanduá tetradactyla provavelmente, no Da sypus novemcinctus certamente, of.oe. é formado, como disposição constante, exclusivamente pelo pilar esquerdo, fato que distingue mais. uma vez o grupo tão curioso e interessante dos Mamíferos que constituem. a Ordem Xenarthra

\section{COMPARATIVE ANATOMICAL RESEARCHES ON THE FORAMEN OESOPHAGICUM OF THE DIAPHRAGM OF SOME WILD MAMMALS OF BRAZIL}

The $A$. has studied the manner of limitation of the foramen oesophagicum (f.oe.) upon 101 diaphramgs of some wild Brasilian Mammals, belonging to the following orders: Marsupialia, Xenarthra, Rodentia, Chiroptera, Carnivora, Artiodactyla and Primates. In the great majority of cases the f. oe. is limited exclusively by the right pillar of the pars lumbalis, which is. thicker than the left one. In Chiroptera and Xenarthra a disposition different from this fundamental and more frequent one was observed. Thus, in Desmodes rufus both pillars are united by a fibrous lamina, with a very smalt muscular bundle separating the oesophagus from the aorta; such disposition resembling that observed by Bertelli and Goldschmidt in another species of Chiroptera; in E. sexcinctus and in C. unicinctus both pillars contribute to form the $f$. oe.; there is, however, a predominance of the left one. In T. tetradactyla the $f$. oe. is also essentially limited by the left pillar. In Myrmecophaga jubata there is a common opening in the diaphragm for the oesophagus and the aorta, without a separating muscular bundle. A common orifice for both organs can also be found in the diaphragm of Choloepus didactylus, much as the $A$. has already observed in Bradypus tridactylus. The differences between the common diaphragmatic opening for the aorta and the oesophagus as observed in $M$. jubata and in some Bradypodidae are outlined by the $A$., as well as a comparison is made between his and other author's observations.

\section{BIBLIOGRAFIA}

\section{(ałé 1938)}

BERTELLI, D. Ricerche sulla morfologia del muscolo diaframma dei mammiferi. - Archivic per le Scienze Medishe, Vol. XIX, N.0 19, 1895.

CICERI, C. Disposizione dei fasci dei pilastri diaframmatici in corrispondenza dell'orifizio esofageo. - Atti R. Ist. Veneto Sc., Lett. et Arti. T. XCII, Parte Sec., Anno Acc. 1932-1933.

CONDORELLI FRANCAVIGLIA, M. - Notizie anatomiche sul "Bradypus tridactylus'. L. var. "ustus" Lesson. - Boll. Soc. Rom. Studi Zool., Vol. II-III, I893-94. 
GOLDSCHMIDT, W. Einige Beobachtungen über die Aorta im Hiatus aorticus diaphragmatis. - Anat. Anz., Bd. 40, N.a 2/3, 1911.

HYRTL, J. Chlamydophory truncati cum Dasypode gymnuro comparatum examen anatomicum. - Denkschriften der k. Akademie der Winssenchaften. Mathematisch. naturwissensch. Klasse, Bd. 9. Wien 1855.

JANSEN, J. Beitrag zur Kenntnis der Zwerchfellinnervation. - Zeitschr. f. Anat. u. Entwicklungsgesch., Bd. 96, 1931.

JAZUTA, K. Baubesonderheiten der Pleurahölen beim Opossum. - Anat. Anz., Bd. 73, 1932.

KOHLBRÜGGE, J. H. F. Die Muskeln und peripheren Nerven der Primaten. - Verhandl. Kon. Akad. v. Wetenschappen. Amsterdam 1897.

KÓRNER, F. Vergleichend-anatomische Untersuchungen über den Faserverlauf der Pars lumbalis des Zwerchfells zur Bergrenzung des Hiatus oesophageus bei Säugetieren. - Morphol. Jahrb., Bd. 61, 1929.

- Die Pars lumbalis diaphragmatis des Seelöwen und ihre Ahnlichkeit mit der des Menschen. - Morphol. Jahrb., Bd. 68, 1931.

- Beobachtungen am Zwerchfell einiger "Xenarthra" - Morphol. Jahrb., Bd. 7I. H. I/2, 1932.

LE DOUBLE, A. F. Traité des Variations du Système Musculaire de I'Homme. - T. I. 1897.

LOCCH1, R. Canal aorticoesophageano do "musculus diaphragma" no "Bradypus tridactylus' - Rev. Biol. Hyg. de S. Paulo, Vol. I, Fasc. 3, 1928.

- Observations sur le "musculus diaphragma" chez le "Bradypus tridactylus" - C. R. Ass. Anat., XXV Reun., Amsterdam, pgs. 203-21I, 1920.

-- Observações sobre ○ musculus diaphragma" no "Bradypus tridactylus". - Ann. Fac. Med. S. Paulo, Vol. VI, pgs. 3-20, 1931.

- Observations sur la "pars lumbalis" du "m. diaphragma" chez le "Dasypus", Rev. Biol. Hyg. S. Paulo, Vol. 5, n. I, pgs. 4l-43, 1934.

MURIE, J. On the habits, structure and relations of the three-banded Armadillo ("Tolypeutes conurus", Js. Geoff.). Transactions of the Linnean Society of London, Vol. 30, 1874.

NAGLIERI, F. Note anatomiche sul Nutria, "Myopotamus coypus" Apparecchio locomotore. - Parte Seconda. - Miologia. - Arch. Ital. Anat., Vol. 30, fasc. 3, 1932.

NISHI, S. Muskeln des Rumpfes, in Handb. der vergleichenden Anat. der Wirbeltiere de Bolk, Göppert, etc., Bd. V, 1938.

OWEN, R. On the anatomy of vertebrates Vol. III. London 1868.

PANCRAZI, G. La "Pars lumbalis" ed il "Centrum tendineum" del Diaframma dei Mammiferi" - Atti Soc. Mat. Modena. Serie VI, Vol. X(LXII) 1931.

POUCHET, G. Mémoires sur le grand Fourmilier ("Myrmecophaga jubata" Linné). Paris 1874 (cit. por Körner, 1932).

SCHULTE, H. v. W. Anatomy of a Foetus of "Balaenoptera borealis". - Memoirs of the American Museum of Natural History, New Series, Vol. I, Part IV, 1916.

SOMMER, A. Das Muskelsystem des Gorilla. - Jenaische Zeitschr. f. Naturwissensch., Bd. 42, 1907.

SPERINO, G. Anatomia del Cimpanzé. - Torino, 1897.

STEWART, T. D. The musculature of the anthropoids. I. Neck and trunk. - American Journ. of Phys. Anthropol., Vol. 21, 1936.

TESTUT, L. Myologie de I'"Ursus americanus" - Internationale Monatsschr. f. Anatomie u. Physiologie, 1890.

WINCKLER, G. Configuration et architeture des piliers du diaphragme. - Arch. Anat. Histol. Embr., 1926. 